\title{
COMPETÊNCIAS INFOCOMUNICACIONAIS: estrutura conceitual e indicadores de avaliação'
}

RESUMO O objetivo deste artigo é contribuir com o desenvolvimento teórico e aplicado da área de Alfabetização Informacional, considerando mudanças proeminentes no ambiente informacional, como a cultura de participação e a construção colaborativa de conhecimento. Trata-se de um ambiente que demanda competências em informação, mas também habilidades para interagir e relacionar-se: competências em comunicação. $O$ artigo situa as competências infocomunicacionais teoricamente, articulando as três principais bases que sustentam este estudo: a Alfabetização Informacional (Alfin), a New Media Literacy (NML) e a Metaliteracy. A partir da sistematização desses conceitos, propõe-se uma estrutura em termos de categorias de onde emergem indicadores úteis à avaliação das competências. Os indicadores foram convertidos em questões, apresentadas a estudantes de pós-graduação de quatro países, de cujas respostas extraíram-se evidências de suas competências em termos de informação e comunicação. Os indicadores, baseados na estrutura conceitual, mostraram-se adequados para se conhecer o comportamento infocomunicacional contemporâneo, a partir do qual se manifestaram competências mais ou menos desenvolvidas. Os resultados salientaram uma forte tendência para a aprendizagem e o trabalho em colaboração, embora nem todas competências inerentes encontrem o mesmo nível de desenvolvimento, com destaque negativo para o relacionamento intercultural.

Palavras-chave: Competências infocomunicacionais. Indicadores de avaliação. Alfabetização informacional. New Media Literacy. Metaliteracy.

* Doutora em Comunicação e Cultura Contemporâneas pela Universidade Federal da Bahia, Brasil., ambos pela UFBA. Pós-doutoramento pela Universidad Carlos III de Madrid, Espanha. Docente permanente no Programa de Pós-Graduação em Ciência da Informação e colaboradora no Programa de Pós-Graduação em Comunicação e Cultura Contemporâneas, ambos na Universidade Federal da Bahia, Brasil.

E-mail: jussarab@gmail.com.

\section{INTRODUÇÃO}

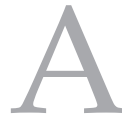
sociabilidade pós-moderna pode ser caracterizada por práticas que valorizam o compartilhamento de conteúdo, a conectividade constante entre as pessoas e a participação em processos sociais de seu interesse. Enquanto a noção de criação no modernismo en-

I Com apoio do CNPq, através do Programa Bolsa de pós-doutoramento no exterior (PDE), e da UFBA, através do Programa de Apoio a Jovens Doutores (Propesq 2016). fatizava o artista ou escritor trabalhando isoladamente em narrativas lineares, o pós-modernismo encaminha-se à multiplicidade de ideias, estilos e atores dispersos, mas trabalhando em rede em ambientes descentralizados. A forma como isso é feito foi impactada pelas possibilidades geradas por instrumentos vinculados à Web Social. Depreende-se, portanto, uma sociabilidade fortemente amparada na capacidade de gerir informação e relacionar-se com o outro através dos recursos digitais, o que demanda competências em informação e em comunicação. 
Embora a área de Alfabetização Informacional (Alfin) considere a capacidade de comunicar a informação como inerente em suas principais definições, a competência em comunicação não foi explorada conceitualmente pela área. A comunicação integra o conjunto de competências que diariamente as pessoas empregam para resolver problemas, participar de processos sociais e serem efetivas em todos os aspectos da vida cotidiana (CATTS; LAU, 2008). Aliado a isso, a capacidade de interagir com pessoas via dispositivos eletrônicos será cada vez mais necessária numa sociedade sob a égide da informação distribuída e do trabalho colaborativo.

A aceleração do fluxo informacional tem propiciado que muitas vezes a informação necessária não chegue a ser registrada, ela está com seu criador ou, mais, com seus criadores, considerando o dinamismo da produção em rede. Assim, as já clássicas competências em informação - saber buscar, avaliar e gerir informação - continuam importantes e pertinentes. Não se pode abrir mão delas. Mas é necessário acrescentar competências para interagir, para relacionar-se, ou como chamamos aqui, competências em comunicação. A convergência e inter-relação entre competências em informação e em comunicação leva à expressão "competências infocomunicacionais" (BORGES, 2013).

As duas áreas (Informação e Comunicação) têm fronteiras tênues e permeáveis. Neste trabalho, para fins de organização das ideias, as competências em informação aparecem ligadas ao conteúdo, enquanto as competências em comunicação dizem respeito às relações, ao ato comunicativo (BORGES; OLIVEIRA, 2011). Enquanto a informação exige a produção de sentido a partir de dados, a comunicação exige a produção de relações a partir da informação (MUCCHIELLI, 1998)

Em uma sociedade crescentemente pautada pela conexão em tempo real, as competências infocomunicacionais são determinantes. Por exemplo, repassar informação inverídica por redes sociais pode ser tão danoso quanto não informar uma catástrofe natural em situações de emergência. Todos os dias nas redes sociais circulam informações falsas e outras importantes, boatos vazios e questões relevantes. Portanto, não se trata apenas de avaliação da informação (recebida), trata-se também de avaliação da comunicação (emitida e intercambiada) e, portanto, da responsabilidade de cada um en- quanto distribuidor, produtor e colaborador em rede. "Esta sociedad actual cuenta efectivamente con un componente tecnológico muy fuerte, pero además exige unas formas diferentes de participar, comunicarse y colaborar en la red, características [...] modifican sustancialmente las llamadas competencias informacionales (ALFIN)." (FERNÁNDEZ-VILLAVICENCIO, 2012, p.19)

Neste trabalho, a principal base conceitual das competências em comunicação vem dos estudos de New Media Literacy. Esses estudos vêm evoluindo de uma perspectiva que enfatizava o senso crítico do consumidor frente aos produtos midiáticos (media literacy) para o reconhecimento de que este consumidor também vem se convertendo em um produtor (prosumidor). Portanto, além da criticidade necessária sobre sua própria produção, emergem aspectos de distribuição (quem é o público-alvo da produção?), de participação (com quem engajar-se?), de criação (com quem produzir?). Todos esses aspectos reclamam a capacidade de relacionar-se com o outro e produzir junto, aproveitando as possibilidades das redes sociais online. (BORGES, 2017)

Este foco na produção colaborativa de conhecimento em comunidades online é compartilhado pela Metaliteracy: "While information literacy prepares individuals to access, evaluate, and analyze information, Metaliteracy prepares individuals to actively produce and share content through social media and online communities." (MACKEY; JACOBSON, 2011, p. 62). Assim, os conceitos oriundos da Metaliteracy conjugados à Alfin e New Media Literacy fornecem a base de sustentação teórica do trabalho.

Além de sistematizar essas questões, este artigo debruça-se na possibilidade de avaliar as competências. De acordo com Santos e Casarin (2014), a comunicação da informação (embora presente desde 2000 entre os parâmetros da Association College \& Research Libraries para Alfin) não é abordada nos instrumentos de avaliação levantados pelas autoras. Assim, esta investigação pode contribuir para sanar esta lacuna, porque propõe-se, também, a desenvolver indicadores para as competências infocomunicacionais.

O desenvolvimento de indicadores de mensuração não tem a presunção de indicar as competências que as pessoas devem ter, mas de fornecer parâmetros para analisar $\mathrm{o}$ comportamento infocomunicacional hodierno apontando elementos a serem considerados 
em políticas e estratégias voltadas à formação de cidadãos partícipes desta sociedade crescentemente infocomunicacional.

O artigo está organizado em três blocos principais: o primeiro busca situar o assunto teoricamente, amparado nas três bases que sustentam o estudo: a Alfabetização Informacional (Alfin), a New Media Literacy (NML) e a Metaliteracy. O segundo bloco descreve a estratégia metodológica adotada na pesquisa. O último bloco centra-se na discussão dos resultados empíricos e as principais conclusões geradas a partir da investigação.

\section{COMPETÊNCIAS INFOCOMUNICACIONAIS REPESENSADAS A PARTIR DA ALFIN, NML E METALITERACY}

Com a emergência das chamadas tecnologias de informação e comunicação (TIC), no final do século passado muitos programas se voltaram à alfabetização digital. De fato, considerando-se o volume e variedade de informações em ambientes digitais, o domínio de ferramentas de acesso e gestão dos conteúdos se coloca como um pré-requisito à participação social (CATTS; LAU, 2008). Claro está que as pessoas podem empregar competências infocomunicacionais independente das TIC, mas é inegável o papel que assumiram na sociedade como mediadoras à informação e à comunicação.

Por isso, neste trabalho observamos as competências infocomunicacionais em ambientes digitais. Contudo, não se deve confundir essas competências com habilidades digitais. Essas habilidades para operar recursos e sistemas são subjacentes, mas insuficientes. Analogicamente, seria o mesmo que confundir a habilidade de utilizar uma caneta com a competência de redigir textos. Assim, se o digital é o ambiente de observação, as competências em seu aspecto mais comunicativo, social e participativo são o foco de análise.

It moves us away from individualist approaches, which seek to understand how an individual engages with information, and towards conceptualising how the phenomenon is constituted by practice architectures, i.e. the sayings, doings and relatings, that shape the information landscape, orienting and orchestrating the practices of the social site towards particular ways of knowing and particular forms of knowledge. (LLOYD, 2012, p. 774)

A área de conhecimento que engloba esses estudos é a alfabetização informacional (Alfin). No Brasil, a maior parte dos estudos vem adotando a expressão "competência em informação", embora encontrem-se trabalhos com a mesma temática sob a expressão "letramento informacional" e outras terminologias. Neste trabalho, segue-se a linha espanhola que identifica a área de estudos por Alfabetização Informacional (Alfin), tendo por objetivo a promoção de competências em informação. Assim, as competências infocomunicacionais referem-se à convergência de conhecimentos (saber), habilidades (saber-fazer) e atitudes (saber-ser) que se deseja desenvolver frente à informação e à comunicação ao longo de um processo de alfabetização informacional.

A Unesco, por sua vez, vem utilizando a expressão media and information literacy (MIL), advogando que o compartilhamento de informação e debates jogam um papel vital no desenvolvimento da cultura democrática e de uma sociedade civil ativa, pois propiciam a criação de uma esfera pública "where issues of importance to the community are discussed and debated, and where information essential to citizen participation in community life is exchanged" (MOELLER et al., 2011p. 7). Parece, portanto, que há dois componentes interdependentes nesse processo: competências em informação (busca, avaliação, uso) e competências em comunicação: relacionar-se com pessoas para trocar, discutir, participar, aprender e gerar conhecimento em colaboração.

As competências em comunicação alinham-se aos conceitos discutidos sob a New Media Literacy ${ }^{2}$ que, de acordo com Jenkins (2009)

\footnotetext{
2 As media literacy advocates have claimed during the past several decades, students also must acquire a basic understanding of the ways media representations structure our perceptions of the world, the economic and cultural contexts within which mass media is produced and circulated, the motives and goals that shape the media they consume, and alternative practices that operate outside the commercial mainstream. Such groups have long called for schools to foster a critical understanding of media as one of the most powerful social, economic, political, and cultural institutions of our era. What we are calling here the new media literacies should be taken as an expansion of, rather than a substitution for, the mass media literacies. (JENKINS, 2009, p. 31)
} 
são habilidades sociais, formas de interagir com uma comunidade e não apenas habilidades individualizadas para expressão pessoal: "We must push further by talking about how meaning emerges collectively and collaboratively in the new media environment and how creativity operates differently in an open-source culture based on sampling, appropriation, transformation, and repuposing." (JENKINS, 2009, p. 32)

Para Fernández-Villavicencio (2012), as competências necessárias para esta nova sociedade digital e em rede não estão incluídas ou não estão tratadas com a profundidade necessária nos tradicionais estudos de Alfin. Assim, nossa abordagem vai ao encontro da linha defendida por Mackey e Jacobson (2011), que advogam pela permanência da Alfin como catalizadora das multialfabetizações, mas incluindo competências para produzir e compartilhar conteúdo em colaboração através de mídias sociais e comunidades online:

\begin{abstract}
A habilidade de acessar criticamente diferentes competências e reconhecer a necessidade de integrá-las no ambiente informacional atual é uma metaliteracy. Essa abordagem metacognitiva desafia a confiança na competência em informação baseada no ensino de habilidades e muda o foco para a aquisição do conhecimento em colaboração com outros. O indivíduo metaliterato tem a capacidade de adaptar-se a tecnologias mutantes e ambientes de aprendizagem, enquanto combina e compreende as relações entre competências relacionadas. Isto requer um alto nível de pensamento crítico e análise sobre como nós desenvolvemos nosso próprio conceito de competência em informação como aprendizes metacognitivos em ambientes abertos e mídias sociais. (MACKEY; JACOBSON, 20I4, p.2, tradução nossa)
\end{abstract}

Assim, enquanto a alfabetização (informacional) preocupa-se em promover competências para que as pessoas possam aproveitar, apropriar-se e usar as informações para proveito próprio ou coletivo; a Metaliteracy direciona-se à apropriação do próprio ciberespaço, como um ambiente rico e em constante (re)criação, no qual as próprias competências têm de ser continuamente repensadas. A abordagem da Metaliteracy não é de promover uma nova lista de competências desejáveis, mas destacar que uma sociedade pautada na participação e na construção coletiva do conhecimento demanda sujeitos capazes de reavaliar suas competências e as rearticular em cada contexto.

A reflexão sobre as competências exige capacidade metacognitiva para compreender suas potenciais aplicações em distintos contextos (profissionais, pessoais, cidadãos etc.) e desenvolvê-las ou conectá-las com as de outras pessoas em situações múltiplas e específicas (JACOBSON; GIBSON, 2015). “A metacoginição compreende a capacidade de reflexão do indivíduo sobre os próprios processos de pensamento, em especial, o processo de construção do conhecimento." (GASQUE, 2017, p. 178)

Isso tem uma aplicação objetiva no ensino de competências infocomunicacionais, por exemplo, porque uma coisa é mostrar fontes e ensinar estratégias de busca e seleção da informação; outra é promover a compreensão do que está implicado nesta ação em termos de conhecimentos, habilidades e atitudes: o que, como e porque se realiza determinada atividade.

A articulação contextual e teórica entre os principais conceitos que embasam esta investigação foi desenvolvida com mais detalhe em dois trabalhos anteriores (BORGES; GARCÍA-QUISMONDO, 2017; MARZAL GARCÍA-QUISMONDO; BORGES, 2017), o que permite, aqui, focar as competências e seus indicadores. Essas competências e indicadores são sintetizados no Apêndice A e representam a interpretação e categorização das competências infocomunicacionais.

A estrutura conceitual que alimenta as categorias e indicadores pode ser sumarizada pela Figura 1. Essa Figura representa espacialmente a organização das competências em quatro quadrantes: no eixo horizontal, das competências em informação para as competências em comunicação; e no eixo vertical, da alfabetização para a meta-alfabetização (Metaliteracy). Algumas competências perpassam os quadrantes, porque envolvem tratar com conteúdos, mas também (em maior ou menor medida), relacionar-se com pessoas. A fronteira da metacognição também permite o trânsito das competências. Por isso as linhas são pontilhadas, com os quadrantes representando a localização mais habitual das competências, antes que sua localização fixa. 
Figura 1 - Estrutura conceitual das Competências Infocomunicacionais

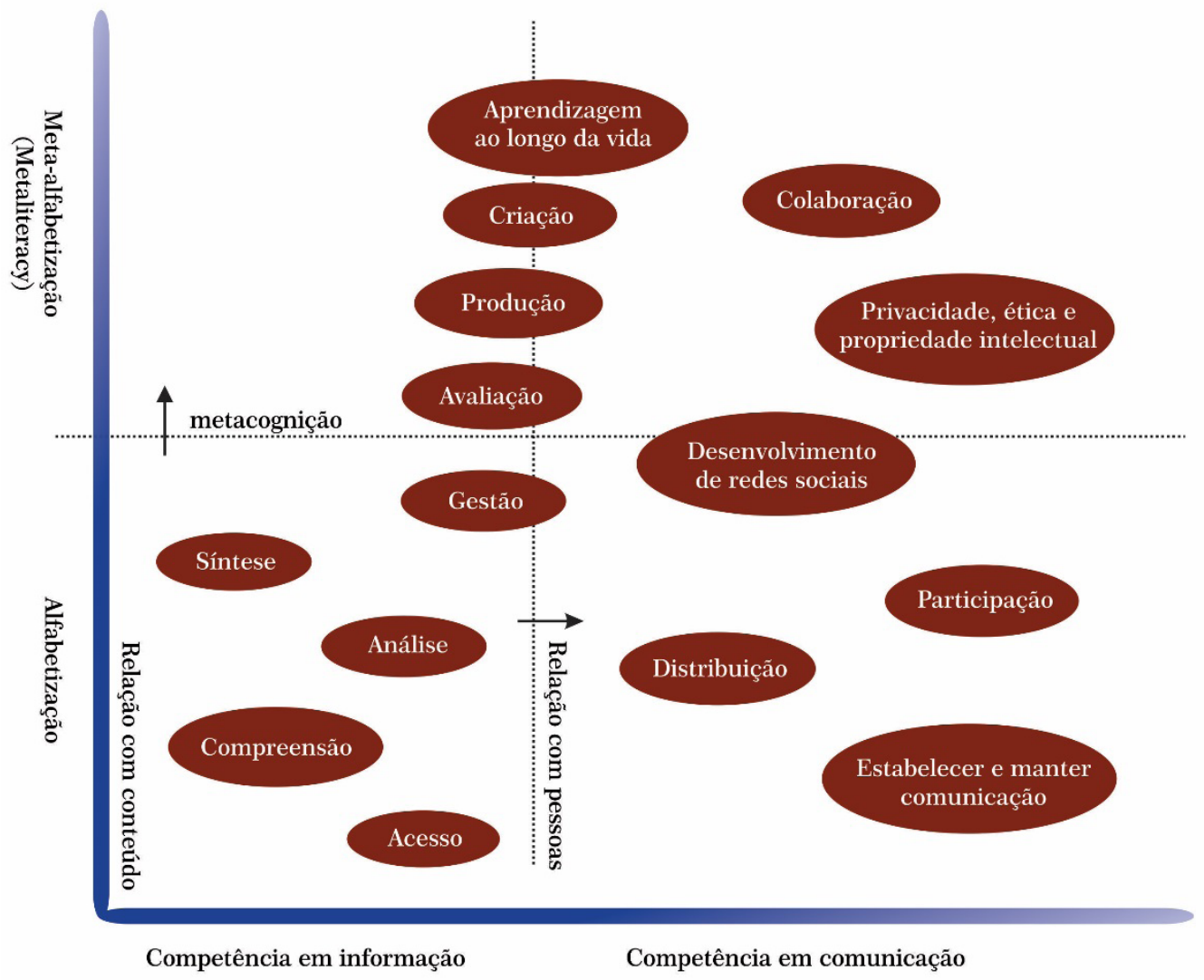

Fonte: construção da autora, 2017

As subseções seguintes explicam a estrutura conceitual sumarizada na Figura 1.

\section{I Competência em informação}

Um crescente número de serviços e produtos indispensáveis para a vida cotidiana estão disponíveis na internet: oportunidades de trabalho, informações sobre eventos culturais, serviços públicos, informações sobre produtos, serviços bancários etc. A possibilidade de acessar e consumir esses conteúdos envolve destrezas técnicas - como operar um computador, aplicativos e redes -, mas principalmente determinar fontes confiáveis e empregar estratégias de busca e seleção da informação. Portanto, mais que competências para operar dispositivos (competências operacionais), são demandas competências em informação: saber quando e como acessá-la, possuir capacidade cognitiva para compreendê-la, analisá-la e sintetizá-la, empregar critérios para avaliála e usá-la para resolver um problema, para conectar com outras informações ou para gerar conhecimento.

A capacidade de compreensão vem sendo desafiada pela confluência de múltiplas linguagens - como as icônicas e gestuais - que se atualizam permanentemente, demandando a captação do significado de conteúdos em fluxo. Compreender informações é não só um ato cognitivo como social, na medida que as relações com outras pessoas nos ajudam a perceber relações entre os conteúdos e contextualizar dados para construir significados. Questões inerentes à compreensão são: o que este texto ou mensagem está querendo dizer? Quais suas possibilidades de sentido? Como meu 
conhecimento se relaciona com essa nova informação? (VARELA; BARBOSA, 2009).

Dessas questões iniciais depreende-se que é sempre necessário colocar os conteúdos sob análise, verificando desde aspectos quantitativos (é necessário mais informação para entender melhor o tema?) até análises mais qualitativas (quem emite a informação é o ator adequado para prestá-la?): “[...] it is vital for individuals to develop media literacy in order to manipulate such technology and for interpreting and processing all kinds of media messages." (CHANG; LIU, 2011, p. 604). A análise ainda envolve questionar: quais os interesses das fontes que fornecem a informação? Como essa informação relaciona-se com outras? Quais as alternativas a este ponto de vista? Há interesses comerciais embutidos?

A síntese refere-se à comparação e contraste entre distintas fontes e conteúdos, e destes com o próprio conhecimento, extraindo disso uma apropriação do essencial. Para Almeida Júnior (2009, p. 97), a própria informação só existe pela apropriação do sujeito:

\begin{abstract}
Como premissa, entendemos a informação a partir da modificação, da mudança, da reorganização, da reestruturação, enfim, da transformação do conhecimento. Assim entendida, ela, informação, não existe antecipadamente, mas apenas na relação da pessoa com - conteúdo presente nos suportes informacionais. Estes são concretos, mas não podem prescindir dos referenciais, do acervo de experiências e do conhecimento de cada pessoa.
\end{abstract}

A síntese, portanto, demanda a capacidade de contínua gestão da informação, no sentido de organizar "peças de informação" dispersas e conectá-las em mapas mentais capazes de gerar sentido e conhecimento. Jenkins (2009, p. 64) trata disso sob o rótulo de multitarefa:

\footnotetext{
They [students] must learn to recognize the relationship between information coming at them from multiple directions and making reasonable hypotheses and models based on partial, fragmented, or intermittent information (all part of the world they will confront in the workplace). They need to know when and how to pay close attention to a specific input as well as when and how to scan the environment to search for meaningful data.
}

A gestão ainda envolve a organização da informação recuperada para um uso atual ou futuro, como a distribuição em pastas por assunto, a renomeação de arquivos com descritores que representam o conteúdo ou mesmo o uso de sistemas de indexação mais elaborados, com possibilidade de múltiplas etiquetagens. Esta gestão pessoal da informação também tem se encaminhado para uma ação socialmente distribuída, quando, por exemplo, nos deparamos com anônimos contribuindo na identificação de pessoas em fotos. A folksonomia ${ }^{3}$, por exemplo, não é uma prática que se inaugura com a web social, mas foi evidentemente impulsionada por ela. A contribuição que espontaneamente as pessoas vêm dando ao acrescentar seu conhecimento sobre uma localização, um evento histórico ou uma descrição mais pormenorizada de um fato que presenciou são informações que colaboram na organização de conteúdos.

Além dessas competências em informação mais basilares, a emergência de tecnologias relacionadas à web social evidenciou a necessidade de competências para a avaliação crítica de conteúdos. De acordo com Cerigatto e Casarin (2017), tradicionalmente a Ciência da Informação foca aspectos como arquitetura da informação, qualidade do conteúdo, análise de credibilidade da fonte e aspectos visuais e de apresentação da informação como critérios para a avaliação. Para as autoras esses padrões são úteis para a pesquisa acadêmica ou profissional, mas não atendem de forma satisfatória quando se trata de avaliar conteúdos midiáticos: "A questão da informação ser veiculada por uma grande empresa aceita no mercado e pelo público, com jornalistas especializados bem capacitados, com textos em um formato aceitável e com design tido como agradável não a torna totalmente confiável, nem credível." (CERIGATTO; CASARIN, 2017, p. 166). Portanto, independente da fonte (oficial, jornalística ou gerada pelo cidadão comum), a criticidade pressupõe a aplicação de critérios de avaliação como distinção do propósito, interesse, validade, correção e veracidade da informação, tanto da explicitada, como da omitida ou tangenciada.

3 "Folksonomia é o resultado da etiquetagem dos recursos da Web num ambiente social (compartilhado e aberto a outros) pelos próprios usuários da informação visando a sua recuperação." (CATARINO; BAPTISTA, 2007) 
É importante compreender que nenhuma informação é neutra, porque sempre é gerada dentro de um contexto (político, ideológico, econômico etc.), com uma intenção e direcionada a alguém, um público ou determinada recepção. A avaliação crítica pressupõe analisar a informação não como expressão da realidade, mas como uma representação desde a perspectiva de alguém, com seus valores e crenças. Wilson (2012, p. 15) ainda acrescenta que é importante atentar para qual informação não está incluída, que vozes são silenciadas e sempre colocar a informação em seu contexto para a construção de sentido.

A competência de julgar e avaliar a informação sempre foi aspecto chave em Alfin; o que se soma agora é a dinamicidade que vem caracterizando os conteúdos em linha, que mudam e evoluem constantemente, demandando capacidade crítica sobre informação em fluxo. Outro aspecto é que também a avaliação da informação se torna social, ou seja, cada vez mais nos apoiamos na recomendação e comentários gerados por outros usuários para tomar decisões. Desde comentários de outros leitores para escolher um livro até opiniões sobre produtos orgânicos de determinada feira, as avaliações alheias mais recentes aportam valor aos conteúdos e constituem sistemas de validação social na Internet. $O$ ambiente informacional contemporâneo é participativo, onde potencialmente indivíduos, autoridades e comunidades podem atuar como fontes, filtros, gestores e avaliadores de conteúdos (SPIRANEC et al., 2016).

Se por um lado, a web social facilitou a produção e disseminação de conteúdos porque prescindem de conhecimentos mais especializados (como de linguagem de programação, por exemplo), por outro expôs fragilidades, como o uso correto da linguagem em cada contexto, a distribuição adequada da informação de acordo com os interesses dos receptores e a necessidade de trabalhar em colaboração.

A web social propiciou também novas formas de produção mais focadas na remixagem e reuso da informação, como editar um vídeo aproveitando textos, sons e imagens produzidos por terceiros, gerar hipertextos conectando informações existentes ou etiquetar materiais alheios. Para Araya e Vidotti (2010), a remixagem não se refere apenas a operações tecnológicas de colagem de informação, mas a uma prática social e comunicacional que constitui e caracteriza a cibercultura.

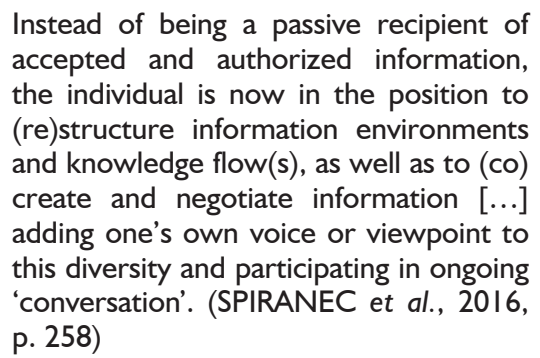

Há um outro nível de produção de conteúdo, no entanto, no qual o indivíduo tem a iniciativa de criar algo novo, seja apontando uma nova perspectiva na resolução de um problema, propondo um modelo de pensamento ou acrescentando uma compreensão crítica sobre determinada questão. Para efeitos de comparação, enquanto a produção centra-se mais na conexão e reaproveitamento das informações existentes, a criação parte disso, mas avança para a geração de inovação e conhecimento.

As competências que se destacou até aqui - acesso, compreensão, análise, síntese, gestão, avaliação, produção e criação - vêm sendo largamente estudadas pela área de Alfabetização Informacional (Alfin). No entanto, para Spiranec e colegas (2016) mudanças no ambiente informacional estão impactando no conceito de competências em informação, como a emergência de informação socialmente construída, a autoridade da fonte mais distribuída, a contínua transformação e reciclagem da informação para reuso e a avaliação social da informação. Pilerot (2016) destaca a emergência de uma perspectiva mais sociocultural nos estudos de Alfin, na qual as competências são vistas como coletivas, incorporadas nas práticas culturais que variam de acordo com cada grupo.

Estas mudanças naturalmente impactam nas competências inerentes à Alfabetização Informacional, pressionando-a para evoluir de competências focadas no consumo e produção de conteúdos para competências mais voltadas ao social, à interação necessária entre pessoas para relacionar-se e construir conhecimento em colaboração. Como diz Marques (2015, p.203) "Uma rede constituída por pessoas, estejam elas no meio digital, ou não, é feita 
de relacionamentos, de comunicação." Assim, neste trabalho, vamos também refletir sobre as competências em comunicação.

\subsection{Competências em comunicação}

Se por um lado as tecnologias sociais expandiram geográfica e temporalmente as possibilidades de comunicação, por outro expuseram as dificuldades de diálogo e compreensão. As tecnologias podem propiciar distintos canais, mas a comunicação é social e pressupõe condições mais exigentes que canais sofisticados, ela exige obter a confiança de alguém para ouvir, compreender e articular argumentos e ideias para dialogar.

\begin{abstract}
O desafio da comunicação reside na sua dimensão dialógica, pois a sua essência reside na relação; quando se aborda a questão da comunicação, trata-se da questão da alteridade e, portanto, a comunicação é, simultaneamente, um processo político. Comunicar é um exercício de cooperação, de negociação, de construção conjunta de sentido, que pressupõe $o$ respeito pelo interlocutor. Pensar a comunicação na era do triunfo da informação e das técnicas implica sublinhar a complexidade da natureza do processo comunicacional com a sua tripla dimensão de questionamento da relação, da alteridade e do receptor. (PASSARELLI et al., 2014, p. I03)
\end{abstract}

Assim, se à primeira vista, estabelecer e manter comunicação soa uma competência singela ou simplista, a verdade é que implica habilidades sofisticadas que vão desde a seleção de um canal e linguagem adequada ao contexto até a abertura para o diálogo intercultural. Para Siemens (2010), os novos oprimidos são os sem habilidades para contribuir em conversações globais, porque se o poder de falar existe potencialmente para todos, o poder de ser escutado ainda é restrito. Por isso, estabelecer e manter comunicação exige atentar para o outro: conseguir sua atenção, propiciar meios para manter o diálogo, respeitar e considerar seu contexto sociocultural.

Ao mesmo tempo que as atuais tecnologias propiciam acessar a uma multiplicidade de pontos de vista, elas também facilitaram a criação de "bolhas de comunicação", em que só se dialoga com os que pensam igual. Para Siemens (2010, p. 94) essa ruptura de diálogo representa um risco para a sociedade civilizada:

\begin{abstract}
A influência moderada da diversidade perde força quando podemos moldar os espaços de diálogo para que se encaixem com nossas crenças. É hora de a diversidade acidental dar passagem à diversidade intencional. Devemos buscar ativamente pontos de vista dos demais para criar um todo unificado.
\end{abstract}

A busca ativa a que se refere Siemens evidencia a compreensão do conceito de comunicação que se utiliza neste trabalho. Não se trata da recepção passiva ou transmissão acrítica de informações, mas da comunicação pelo seu viés social, onde a relação construída entre os sujeitos é mais importante que o conteúdo que circula entre eles.

O produtor de um conteúdo pode fazê-lo sem intenção de distribuição, mas isso é cada vez mais incomum sob a cultura de participação, na qual as pessoas querem ver suas produções comentadas, curtidas, compartilhadas. De acordo com Jenkins (2009), um terço dos adolescentes norte-americanos compartilha suas criações online. Muitas escolas incentivam a produção de textos e de mídias, mas raramente discute-se o compartilhamento: o que se pode compartilhar, quando e sob tais condições.

Assim, a competência em distribuição envolve considerar o público-alvo, o canal ou ferramenta mais adequada para cada mensagem ou público, considerar o contexto (cultural, religioso, econômico etc.) em que está este público e ainda atentar para o formato de apresentação mais adequado. Um dos principais problemas observados quanto ao aspecto da distribuição é a retransmissão de informações recebidas de outros sem avaliação. Muita informação falsa, enviesada ou manipulada circula atualmente na rede porque é fácil usar ferramentas de distribuição, mas falta desenvolver competências críticas de disseminação de conteúdos.

A disseminação eficaz também significa saber o que não compartilhar. Em situações que envolvem privacidade e segurança, por exemplo, manter o controle sobre a informação explicita essa competência. Os nativos digitais costumam demonstrar familiaridade com as ferramentas (competências operacionais) para postar, comentar ou compartilhar informações, mas 
muitas vezes colocam em risco sua segurança e de outros, pois ainda têm dificuldades em discernir as ameaças que esses atos podem representar (BORGES, 2017).

As competências em comunicação devem considerar ainda a capacidade de participar interativa e conscientemente em ambientes de mídias participativos, considerando a vivacidade de debates que propiciam. Como salienta Jenkins (2009), a cultura participativa transfere o foco das competências da expressão individual para o envolvimento comunitário. Isso demanda desde a identificação de espaços e ferramentas adequados para participar, até a intervenção em si com comentários, informações ou discussão, sempre tendo por base o respeito à razoabilidade necessária à interação. Esse exercício de debate e negociação pode, inclusive, promover o desenvolvimento de competências para o trabalho colaborativo e o pensamento crítico (MOORE et al., 2015).

Se considerar o contexto do interlocutor é importante para começar uma comunicação, torna-se imprescindível para desenvolver redes sociais saudáveis em ambientes digitais, onde o respeito à diversidade precisa equilibrar-se com a afirmação da identidade.

\begin{abstract}
[...] el espacio virtual permite al usuario construirse identidades digitales múltiples y de dominio público, que debe saber gestionar $y$ al mismo tiempo ser consciente del alcance y difusión e impacto de las actuaciones que lleve a cabo en torno a los mismos y que pueden afectar a su propia privacidad y a la de otras personas. (FERNÁNDEZVILLAVICENCIO, 20I2, p.26)
\end{abstract}

Desenvolver redes sociais também implica a abertura para participar comunidades eletrônicas para conhecer pessoas e interagir, conhecer e respeitar as regras de relacionamento, escutar, argumentar e defender opiniões de forma respeitosa, além de estar atento a aspectos como visibilidade, reputação e privacidade suas e de outros.

Se houve momento em que a Alfabetização Informacional vinculava-se mais às competências de acesso e apropriação da informação (busca, avaliação e uso), as pesquisas atuais apontam que a questão chave atualmente é trabalhar e gerar conhecimento em colaboração. Como salientam Spiranec, Zorika e Kos (2016, p. 253):

\begin{abstract}
Web 2.0 spawns a new paradigma precisely because its architecture of participation encourages a non-elitist social construction of knowledge in which the authority for the validation of knowledge rests with decentralized and diverse networks employing a great variety of approaches to arriving at knowledge.
\end{abstract}

Isso pressupõe outras competências, como engajar-se em processos de construção de conhecimento coletivos, mobilizar redes sociais para conseguir ajuda, estabelecer parcerias de trabalho, discutir, argumentar ou debater para chegar à resolução de problemas com os demais, compreender e praticar a forma de argumentação de um coletivo específico: "Um domínio de conhecimento pode ser um domínio científico, acadêmico ou profissional e tem estruturas únicas de comunicação e publicação, tipos específicos de documentos, terminologia e estrutura de informação específicas." (MARQUES, 2015, p.203)

Por fim, o aspecto da aprendizagem ao longo da vida pode ser caracterizado como a iniciativa de empregar as competências infocomunicacionais para mantê-las atualizadas (metacompetências) e aprender de forma permanente para alcançar objetivos pessoais, acadêmicos ou profissionais.

\begin{abstract}
Nossa habilidade para aprender o que vamos necessitar amanhã é mais importante que o que sabemos hoje. Quando se necessita conhecimento, mas não se dispõe dele, a capacidade de conectar-se a fontes que satisfaçam essa demanda se converte em decisiva. Posto que o conhecimento segue crescendo e evoluindo, o acesso ao que se necessita é mais importante que o que o aprendiz possua em um dado momento. (SIEMENS, 2010, p. 83)
\end{abstract}

\section{MÉTODO}

O desenvolvimento conceitual e empírico deste trabalho pode ser descrito em três fases que se sobrepõem: 1) estrutura conceitual das competências infocomunicacionais; 2) indicadores de análise das competências; 3) aplicação empírica dos indicadores. 


\section{I. Estrutura conceitual}

Em junho de 2015 começou-se por determinar os termos de investigação tendo em vista o desenvolvimento do projeto de pós-doutoramento "Competências infocomunicacionais: desenvolvimento do conceito e de indicadores de avaliação" no âmbito do grupo de pesquisa Acrópolis da Universidad Carlos III de Madrid. As discussões iniciais levaram à definição das áreas de conhecimento que proporcionariam a base teórica do trabalho, quais sejam: Alfabetização Informacional, New Media Literacy e Metaliteracy. Destas discussões também emergiram conceitos que permeariam toda a argumentação a ser desenvolvida nos meses seguintes, como trabalho colaborativo e conectivismo. Nos dois meses seguintes produziu-se um primeiro texto com o contexto de investigação e as principais convenções e conceitos estruturantes do trabalho (BORGES; GARCÍA-QUISMONDO, 2017).

O desenvolvimento, descrição, discussão e refinamento do esquema conceitual ocupou os quatro últimos meses de 2015, envolvendo tarefas como acompanhamento das últimas publicações importantes sobre os conceitos envolvidos, discussões semanais com o grupo de pesquisa e preparação de comunicações científicas (BORGES, J.; MARZAL GARCÍA-QUISMONDO, 2015).

\subsection{Indicadores de análise}

Com a perspectiva de estabelecer uma ponte de duas vias entre a proposta conceitual sumarizada na seção anterior e a sua verificação empírica, passou-se à construção de indicadores estruturados em categorias de competências (Apêndice A). A construção de indicadores também contou com a revisão de distintos documentos, cujos que forneceram subsídios foram os seguintes:

Normas: ALA - Information Literacy Standards for Higher Education, 2000; Anziil - El Marco para la alfabetizacion en Australia y Nueva Zelanda, 2004; IFLA - Diretrizes sobre desenvolvimento de habilidades em informação para a aprendizagem permanente, 2008; Unesco - Towards Information Literacy Indicators, 2008; Unesco - Towards Media and Information Literacy Indicators, 2010.
Programas: Unesco e Athabasca Univesity - Media and Information Literacy Course, 2015; Mackey e Jacobson - Goals and Learning Objetctives - Metaliteracy.org.

Pesquisas: Marzal - Indicadores: Competências em información para la lectura em biblioteca escolares (MARZAL GARCÍAQUISMONDO et al., 2008); OCDE - Guide to Measuring the Information Society (ORGANISATION FOR ECONOMIC COOPERATION AND DEVELOPMENT, 2011); Ferrés e Piscitelli - La competencia mediática, 2012 (FERRÉS PRATS; PISCITELLI, 2012); European Commission - The Digital Skills Indicators (EUROPEAN COMMISSION, 2014); Pisté Beltrán - Evaluación de competencias en información para el aprendizaje y la investigación (PISTÉ BELTRÁN, 2015)

Também foram averiguadas outras pesquisas citadas por Lee e colegas (2015) com a perspectiva de identificar as estratégias metodológicas adotadas por trabalhos com objetivos empíricos similares ao nosso. Em resumo, foram úteis: as questões relacionadas com o impacto da TV e da publicidade entre estudantes envolvidos com estudos midiáticos em Singapura, de Phang e Schaefer (2009); o método de entrevistas e questionários anônimos para obter respostas relativas à privacidade de adolescentes do Reino Unido, de Livingstone e Helsper (2009); a pesquisa de Hargittai (2005) sobre a operação de recursos de internet com 100 usuários escolhidos aleatoriamente; a experiência de Chang e Liu (2011) com 1539 alunos que auto-avaliaram suas competências utilizando o Media Literacy Self-Assessment Scale (MLSS); e o modelo de tomada de decisões para a avaliação de e-literacy (BRANDTWEINER et al., 2010).

A abordagem subjacente a cada indicador é que: a) estivesse corretamente filiado às respectivas categorias e, portanto, embasado em uma argumentação teórica que o justificasse e relacionasse com o conceito que se queria medir; b) o indicador fosse capaz de efetivamente medir o que se queria averiguar; c) a confiabilidade, no sentido de o indicador produzir iguais resultados, independentemente de onde se aplique (MARZAL GARCÍA-QUISMONDO, 2008). A proposta é desenvolver indicadores válidos para identificar as competências, mais que determinar quais e em que nível as pessoas as devem ter. 


\subsection{Aplicação empírica}

Para a aplicação empírica, em fevereiro de 2016, os indicadores foram convertidos em perguntas ou afirmações voltadas ao público acadêmico sobre seu comportamento informacional e comunicacional. Algumas perguntas foram adaptadas das pesquisas citadas na fase anterior. Outras foram criadas para esta pesquisa em particular. Todas foram submetidas a outros pesquisadores que avaliaram sua pertinência com os indicadores e sua clareza quanto ao que se pretendia descobrir.

As questões foram, então, testadas com três professores (das áreas de Informação e Comunicação) e três alunos em distintos níveis de formação (graduação, mestrado e doutorado). Este pré-teste teve por objetivo validar o conteúdo e a construção do questionário. Quanto ao conteúdo, a testagem averiguou se a questão era capaz de levantar informações que atendessem ao indicador respectivo; a validação do conteúdo também atentou à clareza e compreensão das questões, tendo em vista alunos de pós-graduação. Quanto à construção, buscouse validar se o questionário no todo identificava comportamentos nos quais se observassem as competências em informação e em comunicação. Com as questões ajustadas, selecionou-se um instrumento eletrônico de distribuição do questionário direcionados a estudantes de mestrado.

Algumas críticas (LICEA DE ARENAS, 2008) vêm sendo direcionadas ao uso de questionários como instrumento de avaliação de competências, em geral porque levantariam mais a opinião das pessoas sobre suas competências que avaliariam as competências em si. São críticas válidas e que se considerou ao escolher o instrumento de coleta de dados. No entanto, não parece ser o instrumento a causa de tal desvio, mas a construção das questões apresentadas ao pesquisado. Neste trabalho perguntou-se como os alunos se comportam em situações reais e corriqueiras, a partir das quais podese compreender seu comportamento perante a informação e a comunicação.

Walsh (2009) realizou um levantamento das ferramentas (questionários, análises de bibliografia, simulação, auto-avaliação, observação etc.) que vêm sendo utilizadas para avaliar aspectos de Alfin. Após analisar 91 trabalhos desta natureza, concluiu que o melhor instrumento é o que equilibra as possibilidades do pesquisador de administrar a ferramenta com a avaliação adequada daquilo que se quer saber. Assim, enquanto as simulações, por exemplo, têm a virtude de testar as competências em situações muito próximas da realidade, por outro lado têm o inconveniente de restringir-se a populações pequenas, o que limita a generalização dos resultados.

Nesta pesquisa, optou-se pelo questionário de múltipla escolha em plataforma on-line para alcançar uma população distribuída em quatro países. Para minimizar o principal ponto fraco do questionário, que é o levantamento de informações demasiado superficiais, nesta pesquisa investiu-se em questões que avaliassem não apenas as destrezas e habilidades, mas principalmente competências e atitudes em situações reais, questionando-os sobre como haviam reagido na última vez em que avaliaram a informação, envolveram-se em um debate etc. Deve-se reconhecer, de todos modos, que qualquer escolha significa abrir mão de outras possibilidades, e a escolha de um instrumento significa privilegiar algumas fortalezas, mas aceitar as debilidades inerentes.

Um total de 86 estudantes de pósgraduação responderam ao questionário disponível online entre 14 e 31 de março de 2016. Destes, 59 respondentes são de países hispanofalantes: Espanha, México e Uruguai (neste artigo vamos referir-nos a este grupo como hispanos) e 27 são brasileiros.

\section{RESULTADOS}

Um aspecto proeminente do comportamento informacional nesta segunda década do séc. XXI é que as pessoas buscam por informação online antes de descolocarse por produtos ou serviços $(81,6 \%)$. Mesmo quando querem apenas avaliações, dicas ou conselhos de outros usuários, a web é a fonte primordial (Gráfico 1). São dados que demonstram as afirmações de Spiranec e outros (2016) quando destacam mudanças no ambiente informacional no sentido de tornar-se mais participativo, conversacional e colaborativamente construído. 
Gráfico 1 - Fonte de informação sobre produtos e serviços

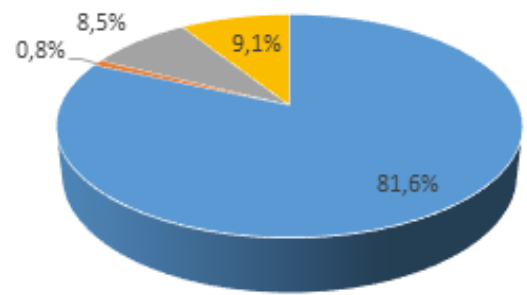

- Primero buscar informação na web sobre o produto ou serviço

- Ligar para uma loja everificar se tem o que necessita

- Ir diretamente à loja paraver ificar se há o produto de que se necessta

- Pedir informações a outras pessoas

Fonte: pesquisa empírica da autora, 2016

As pessoas empregam diferentes critérios para avaliar a informação, sendo a verificação da fonte o mais citado (Gráfico 2). Aqui vale discutir, no entanto, o critério menos selecionado dentre os propostos: diferenciar opiniões de fatos. As notícias factuais propõem-se a uma descrição aproximada da realidade, enquanto a opinião envolve um juízo de valor. O discernimento crítico das informações apresentadas pelos meios de comunicação de massa - que muitas vezes apresentam o posicionamento editorial como fato - é uma questão-chave para os estudos de media literacy. No entanto, com os usuários cada vez mais assumindo a posição de produtores de conteúdos, o discernimento entre fato e opinião é imprescindível perante qualquer fonte.

Pesquisa de Sanchéz-Navarro e Aranda (2011) sobre o uso da internet entre jovens espanhóis apontou que os três principais critérios para confiar na informação on-line são: a) o sentido comum, ou seja, se a informação parece coerente com o que se sabe ou o que é comumente aceito como correto; b) o prestígio da fonte, este vinculado a instituições formais; c) a reiteração, isto é, a comparação entre a informação veiculada em diferentes lugares. Os resultados desta pesquisa, portanto, diferem, ainda que brevemente, provavelmente porque estudantes de pós-graduação estão mais maduros para não se fiar no sentido comum; eles primeiro vão avaliar se quem diz tem credibilidade e idoneidade para emitir a informação $(88,5 \%)$ e numa escala igualmente elevada $(75,3 \%)$ também comparam distintas fontes.

Gráfico 2 - Avaliação da informação

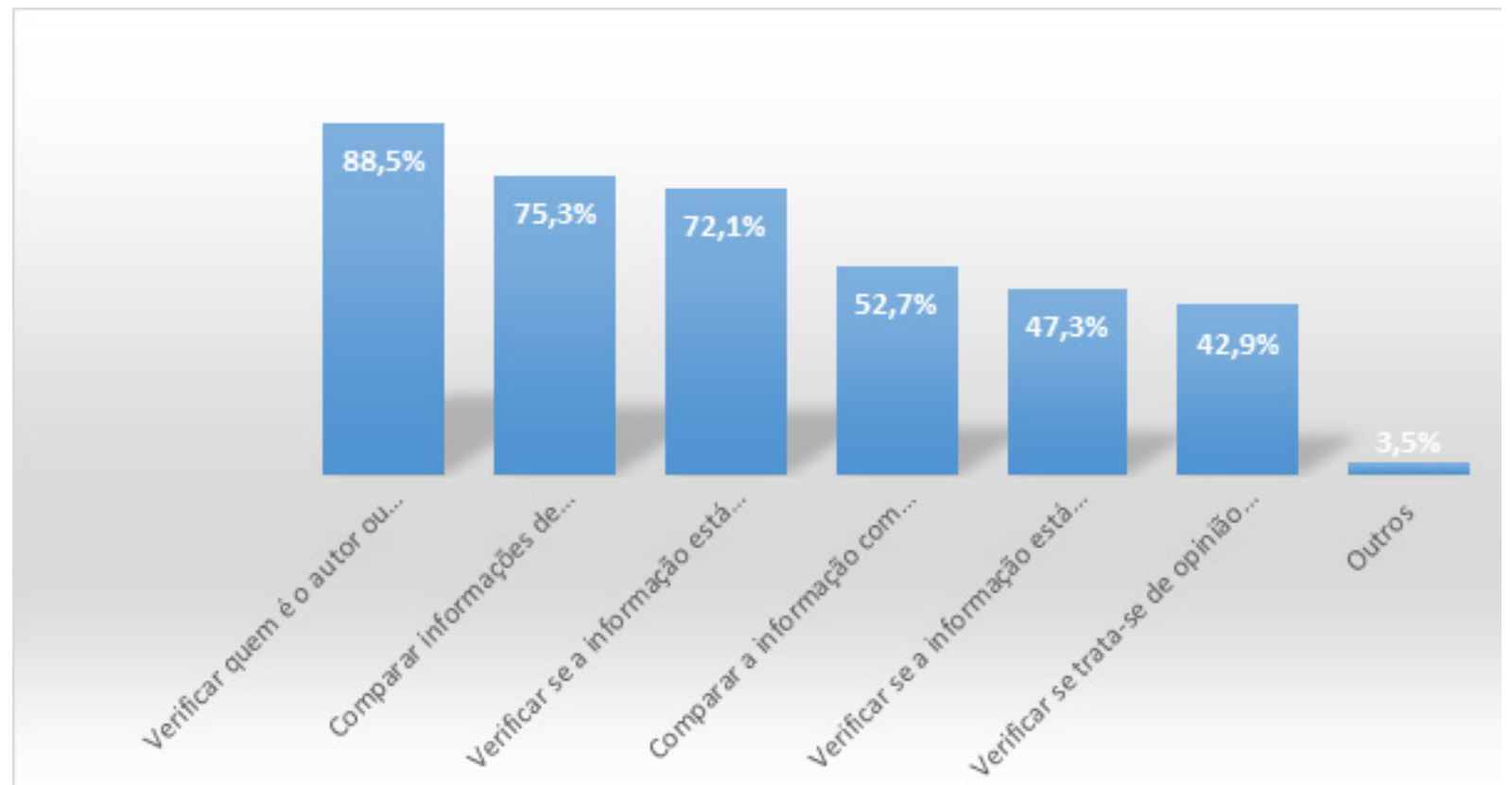

Fonte: pesquisa empírica da autora, 2016 
Sob a perspectiva da alfabetização crítica para a produção de conteúdos, incluímos questões que buscavam conhecer o comportamento informacional quanto à criação em contextos de trabalho colaborativo. De acordo com os dados apresentados no Gráfico 3 , os estudantes demonstram ter um alto comprometimento com o trabalho em grupo; são poucos os que os evitam $(5,4 \%)$, evidenciando que a cultura de participação é uma característica de seu comportamento.
Esse resultado encontra reflexo na pesquisa conduzida por Pilerot (2016) com estudantes de doutorado de países nórdicos europeus, na qual se evidenciou que várias atividades consideradas cruciais para desenvolver competências em informação são associadas com ações coletivas, quando as pessoas fazem coisas juntas. A pesquisa concluiu que a atuação em parceria se constitui em um importante elemento para promoção das competências em informação.

Gráfico 3 - Trabalho em colaboração

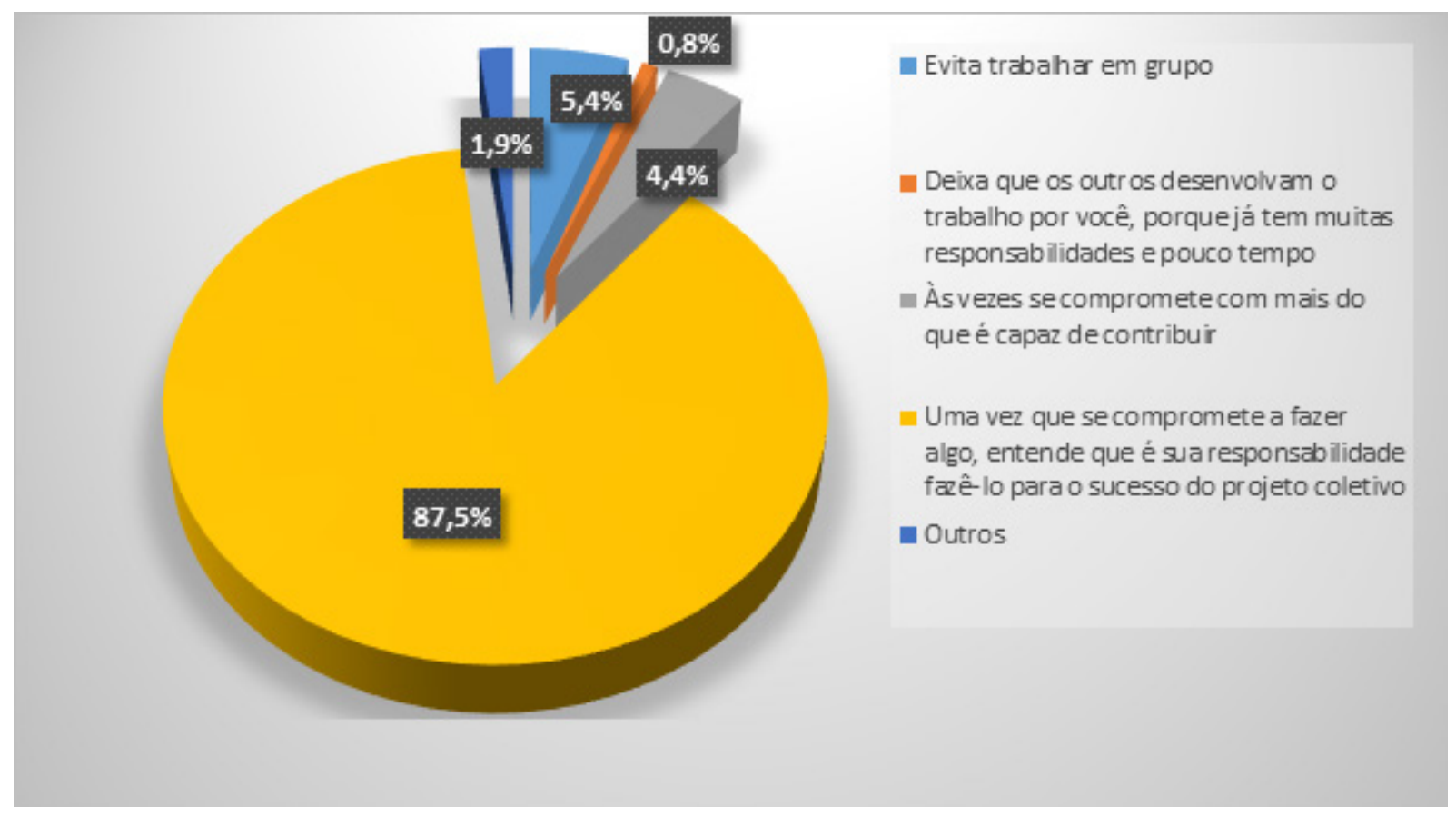

Fonte: pesquisa empírica da autora, 2016

Vislumbra-se um comportamento direcionado ao trabalho em grupos, entendidos como espaços propícios para aprendizagem, seja pelas discussões, pelas possibilidades de debater ideias, textos e autores ou mesmo pelas dicas trocadas entre os participantes. Esse desenvolvimento de competências pela interação também nos remete à capacidade de diálogo, negociação e, portanto, comunicação.

Pesquisa de Head (2015) com recém graduados apontou que a maioria (86\%) reportava a necessidade de desenvolver competências em comunicação interpessoal para uso no ambiente de trabalho, bem como para a sua vida pessoal (67\%). Assim, propusemos questões nas quais o respondente aportava seu comportamento em comunicação em situações cotidianas. Perguntamos, por exemplo, se e como transmitiria a um amigo que encontrou um artigo de seu interesse. $O$ resultado mais relevante (Gráfico 4) não é exatamente como as pessoas comunicariam essa informação, mas a atitude de fazê-lo. Em todas as respostas, a informação seria comunicada instantaneamente, seja enviandolhe o link $(48,7 \%)$, seja enviando o próprio documento $(34,8 \%)$. 


\section{Gráfico 4 - Comunicação}

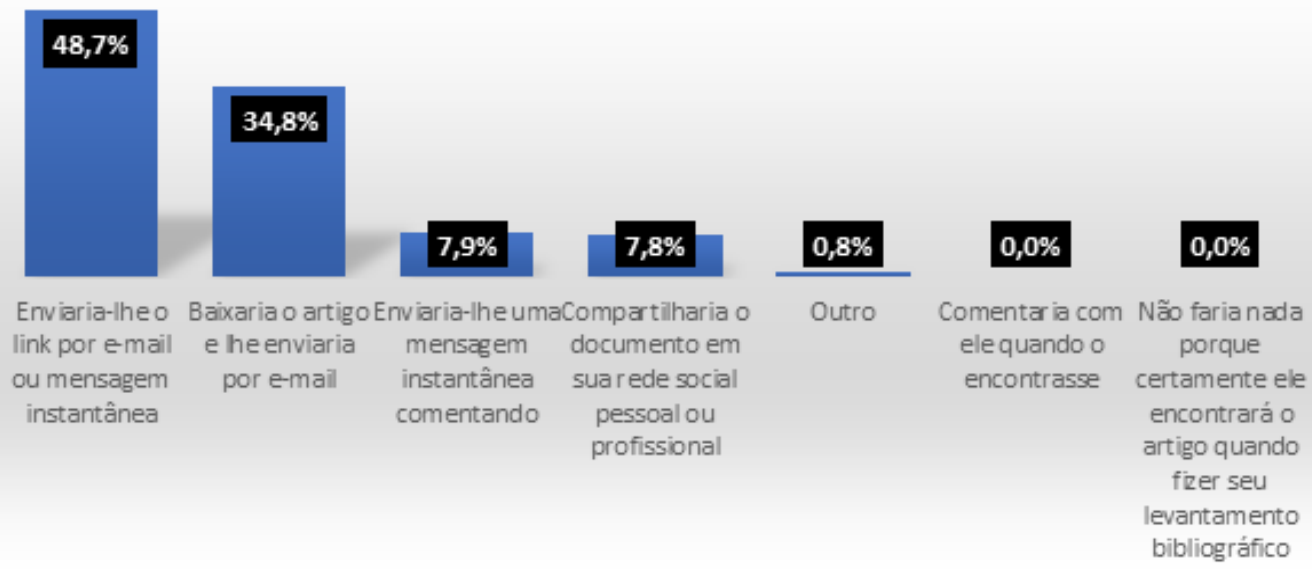

Fonte: pesquisa empírica da autora, 2016

O debate, quando envolve conflito de ideias, testa a capacidade de comunicação de qualquer pessoa, porque demanda quase todas as competências inerentes à comunicação: escuta atenta, compreensão de contexto, análise crítica, exposição clara e respeitosa, linguagem adequada etc. Questionados sobre seu comportamento na última vez que estiveram envolvidos em um debate desta natureza (Gráfico 5), os respondentes disseram respeitar as distintas opiniões, mesmo aquelas que contradiziam as suas $(72,6 \%)$. No entanto, não é desprezível a quantidade de pessoas inflexíveis, seja porque negam-se a questionar seus próprios conceitos $(11,5 \%)$, seja porque tentam impor seu ponto de vista $(9,6 \%)$.

\section{Gráfico 5 - Debate}

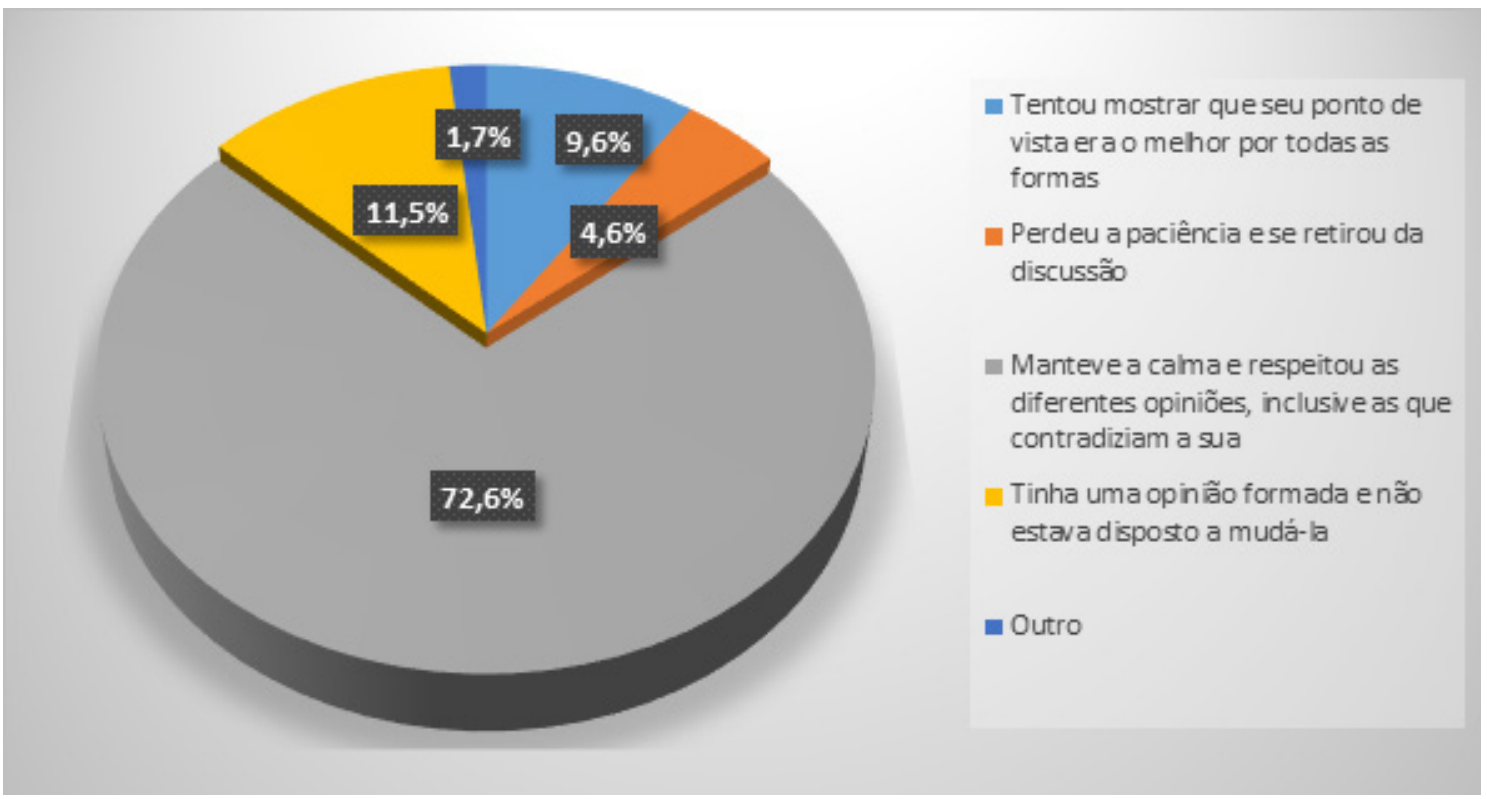

Fonte: pesquisa empírica da autora, 2016 
As possibilidades de informar-se e comunicar-se propiciadas pela internet tornaram possível e fácil a aproximação entre pessoas de todas latitudes e longitudes do globo, mas ao mesmo tempo descortinaram as diferenças e as dificuldades de interação. Entre os participantes da pesquisa é inquestionável a intenção de aproximar-se de culturas diferentes $(66,4 \%)$, mas há que atentar-se aos $20 \%$ de hispanos que não têm sequer o interesse de aproximação (Gráfico 6). Preocupante, no entanto, é a posição de $14,8 \%$ de brasileiros que não se relacionam com culturas distintas por considerar que não vão lhe trazer nenhum benefício. Um país marcado pela diversidade cultural, como o Brasil, que não creia na interação cultural para o intercâmbio de ideias e discussão de ideologias revela as fendas de sua estrutura social.

Gráfico 6 - Relação com culturas diferentes

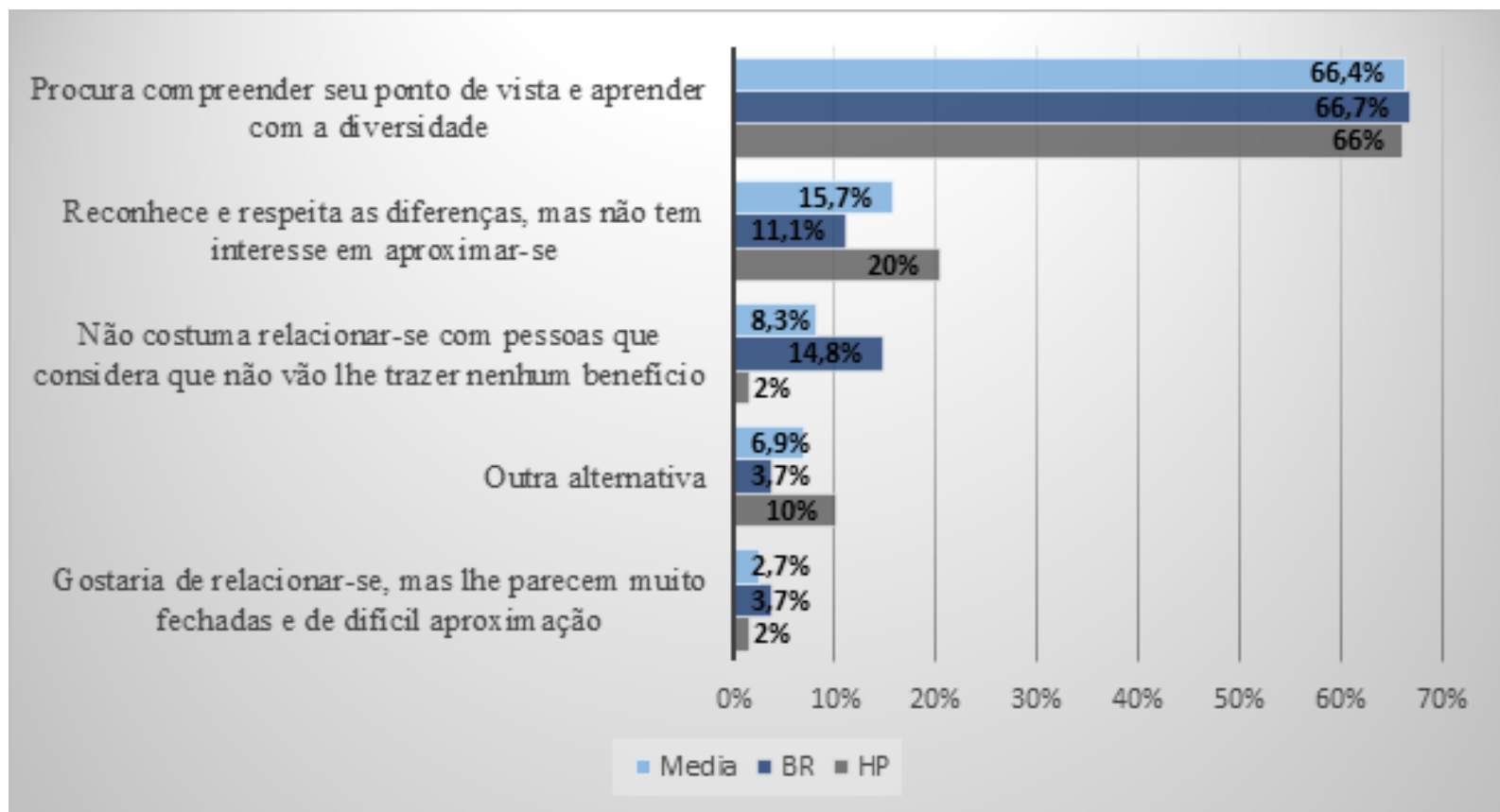

Fonte: pesquisa empírica da autora, 2016

Ao tratar da mediação cultural, Perrotti e Pieruccinni (2014, p.11) comentam que "É preciso criar vínculos simbólicos entre os diferentes, espaços de transição, pontos de convivência que tornam possível o 'viver juntos', em especial em época de mudanças que alteram relações de tempo e espaço, via tecnologias virtuais cada vez mais onipresentes."

\section{CONCLUSÕES}

Uma nova alfabetização que promova as competências infocomunicacionais é estratégica para formar cidadãos capazes de decidir que informação necessitam, que sejam ativos na escolha das fontes e mídias que consomem e protagonistas das intervenções que desejam. Trata-se de uma alfabetização que avança do desenvolvimento de competências para fazer algo - como lidar com os diversos conteúdos (informação) e relacionar-se com pessoas (comunicação) - para competências metacognitivas no sentido de não só saber fazer, mas decidir quando e por que fazer.

Assim, a abordagem proposta pela Metaliteracy permitiu avançar na compreensão das competências infocomunicacionais que estão atualmente sendo demandadas para atuação nas distintas frentes da vida contemporânea: como cidadãos, como profissionais, como seres humanos detentores de direitos e deveres. O 
direito à comunicação, um direito humano de terceira geração, pressupõe o desenvolvimento de competências que permitam aos cidadãos compreender, expressar e debater suas ideias e as de outros. No entanto, enquanto nossas pesquisas (BORGES; MARZAL GARCÍAQUISMONDO, 2015) vêm apontando o avanço das competências para lidar com tecnologias competências operacionais - e para lidar com conteúdo - competência em informação -, a competência em comunicação sempre fica aquém das demais. Os dados empíricos deste trabalho também evidenciam algumas dificuldades, expressas no comportamento de pessoas com alto grau de escolaridade (todos pós-graduandos), mas que em situações de conflito nem sempre estão abertos à negociação e ao debate, que uma cultura democrática pressupõe.

A cultura participativa, refletida nos resultados em geral, não repercute automaticamente no desenvolvimento de competências. Maior participação nem sempre gera melhor comunicação, haja vista o discurso de ódio, de intolerância, de difamação, que muitas vezes se observa em redes sociais e que, em nome da liberdade de expressão, gera incomunicação. Por isso, os estudos de New Media Literacy são relevantes, porque destacam os aspectos culturais e habilidades sociais demandadas atualmente para a comunicação que se engendra em ambientes digitais.

Dificuldades de comunicação também transparecem no diálogo intercultural, o que parece contraditório com o desejo de aprender e trabalhar em colaboração, também evidenciado nos resultados deste trabalho. Há, portanto, uma percepção positiva da construção coletiva de conhecimento, mas preferencialmente com os semelhantes, que não demandam tanta negociação de sentidos.

Sob o ponto de vista teórico-metodológico, o exercício desenvolvido neste trabalho mostrou-se útil para revisar as competências infocomunicacionais: partiu-se de três campos teóricos relativamente bem delimitados Alfin, NML e Metaliteracy - para construirse categorias de competências passíveis de serem verificadas com indicadores; esses foram traduzidos em questões sobre o comportamento infocomunicacional que, por sua vez, levaram aos resultados. Antes que representar um fim, os resultados empíricos foram a mola propulsora para repensar categorias e indicadores que hora se apresentam no Apêndice A. As categorias, por sua vez, representam a estrutura conceitual das competências infocomunicacionais.

Artigo recebido em 06/06/2017 e aceito para publicação em 26/02/2018

\section{INFOCOMMUNICATION LITERACIES: Conceptual framework and evaluation indicators}

ABSTRACT The objective of this article is to contribute to the theoretical and applied development of the Information Literacy area, considering important changes in the informational environment, such as participation culture and collaborative knowledge construction. It is an environment that demands information literacy, but also skills to interact and relate to people: communication literacy. The article situates the infocommunication literacies theoretically, articulating the three main bases that support this study: Information Literacy (Alfin), New Media Literacy (NML) and Metaliteracy. From the systematization of these concepts, it is proposed a structure in terms of categories from which emerge indicators useful for the evaluation of competencies. The indicators were converted into questions, presented to postgraduate students from four countries, whose answers extracted evidence of their literacies in terms of information and communication. The indicators, based on the conceptual structure, were adequate to know contemporary infocommunicational behavior, from which more or less developed competences were manifested. The results have highlighted a strong trend towards learning and collaborative work, although not all inherent competencies are at the same level of development, with negative emphasis on intercultural relationships.

Keywords: Infocommunicational. Communication literacy. Evaluation indicators. New Media Literacy. Metaliteracy. 


\section{REFERÊNCIAS}

ALMEIDA JÚNIOR, O. F. Mediação da informação e múltiplas linguagens. Tendências da Pesquisa Brasileira em Ciência da Informação, v. 2, n. 1, p. 89-103, 2009.

ARAYA, E.; S. VIDOTTI. Criação, proteção e uso legal de informação em ambientes da World Wide Web. São Paulo: Cultura Acadêmica, 2010.

BORGES, J. A contribuição das competências infocomunicacionais ao conceito de Media and Information Literacy. Revista Brasileira de Biblioteconomia e Documentação, São Paulo, v. 13, n. especial, p. 26-47, 2017.

BORGES, J. Competências infocomunicacionais em ambientes digitais. In: BARBOSA, A.F. (Org..) TIC Domicílios 2014: pesquisa sobre o uso das tecnologias de informação e comunicação nos domicílios brasileiros. São Paulo: Comitê Gestor da Internet no Brasil, 2015.

BORGES, J. Participação política, internet e competências infocomunicacionais: evidências a partir de organizações da sociedade civil de Salvador. Salvador: Edufba, 2013.

BORGES, J.; MARZAL GARCÍA-QUISMONDO, M.A. Competencias en información y en comunicación: desarrollo conceptual a partir de la new media literacy. Revista Interamericana de Bibliotecología, v. 40, n. 1, p. 35-43, 2017.

BORGES, J.; MARZAL GARCÍA-QUISMONDO, M.A. Competências infocomunicacionais para acesso e uso da informação.EDICIC, v. 12, p. 1-10, 2015.

BORGES, J.; OLIVEIRA, L. Competências infocomunicacionais em ambientes digitais. Observatorio (OBS*), v. 5, n. 42011.

BRANDTWEINER, R.; DONAT, E.; KERSCHBAUM, J. How to become a sophisticated user: a two-dimensional approach to e-literacy. New media \& society, v. 12, n. 5, p. 813-833, 2010.

CATTS, R.; J. LAU. Towards information literacy indicators Paris: Unesco, 2008.

CERIGATTO, M.P.; CASARIN, HELEN DE CASTRO SILVA. As mídias como fonte de informação: aspectos para uma avaliação crítica. RBBD.Revista Brasileira de Biblioteconomia e Documentação, v. 13, n. especial, p. 155-176, 2017.
CHANG, C.; LIU, E.Z. Exploring the media literacy of Taiwanese elementary school students. The AsiaPacific Education Researcher, v. 20, n. 3, p. 604-611, 2011.

EUROPEAN COMMISSION. Measuring Digital Skills across the EU: EU wide indicators of Digital Competence. Brussels, 2014.

FERNÁNDEZ-VILLAVICENCIO,

N.G.

Alfabetización para una cultura social, digital, mediática $y$ en red. Revista Española de Documentación Científica, v. 35, n. Monográfico, p. 17-45, 2012.

FERRÉS PRATS, J.; PISCITELLI, A. La competencia mediática: propuesta articulada de dimensiones e indicadores. Comunicar: Revista científica iberoamericana de comunicación y educación, $n$. 38, p. 75-82, 2012.

GASQUE, K.C.G.D. Metacognição no processo de letramento informacional. RBBD.Revista Brasileira de Biblioteconomia e Documentação, v. 13, n. especial, p. 177-195, 2017.

HARGITTAI, E. Survey measures of web-oriented digital literacy. Social Science Computer Review, v. 23, n. 3, p. 371-379, 2005.

HEAD, A.J. Project Information Literacy's Research Summary: Lifelong Learning Study, Phase Two and the Online Survey. Phase Two and the Online Survey (February 17, 2015), Washington 2015.

JACOBSON, T.E.; GIBSON, C. First thoughts in implementing the framework for information literacy. Communications in Information Literacy, v. 9, n. 22015.

JENKINS, $H$. Confronting the challenges of participatory culture: Media education for the 21st century Cambridge (Massachussets): Mit Press, 2009.

LEE, L. et al. Understanding new media literacy: The development of a measuring instrument. Computers \& Education, v. 85, p. 84-93, 2015.

LICEA DE ARENAS, J. La evaluación de la alfabetización informacional. Principios, metodologías y retos. Anales de Documentación, v. 10, n. 0, p. 215-232, 2008.

LIVINGSTONE, S.; HELSPER, E. Balancing opportunities and risks in teenagers' use of the internet: The role of online skills and internet selfefficacy. New media \& society, v. 11, n. 8, p. 1-25, 2009. 
LLOYD, A. Information literacy as a socially enacted practice. Journal of Documentation, v. 68 , n. 6, p. $772-783,2012$

MACKEY, T.P.; JACOBSON, T.E. Reframing Information Literacy as a Metaliteracy. College \& Research Libraries, v. 72, n. 1, p. 62-78, 2011.

MACKEY, T.P.; T.E. JACOBSON. Metaliteracy: reinventing information literacy to empower learners London: Facet, 2014.

MARQUES, M. Ação comunicativa e de informação: modelo transdisciplinar para $o$ aprender a aprender. Revista Ibero-Americana de Ciência da Informação, v. 8, n. 2, p. 194-211, 2015.

MARZAL GARCÍA-QUISMONDO, M.A.; BORGES, J. Modelos evaluativos de Metaliteracy y alfabetización en información como factores de excelencia académica. Revista Española de Documentación Científica, Madrid, v. 40, n. 3, p. e184, 2017.

MARZAL GARCÍA-QUISMONDO, M.A.; CALZADA PRADO, F.J.; OSTI, M.V. Criterios para la evaluación de la usabilidad de los recursos educativos virtuales: un análisis desde la alfabetización en información. Information Research, v. 13, n. 4, p. 5, 2008.

MARZAL GARCÍA-QUISMONDO, M.,A. La alfabetización en información como dimensión de un nuevo modelo educativo: la innovación docente desde la documentación y los CRAI. RIED: revista iberoamericana de educación a distancia, v. 11, n. 2, p. 41-66, 2015/06/12 2008.

MOELLER, S. et al. Towards media and information literacy indicators. Paris: Unesco, 2011.

MOORE, C. et al. Integrating Information Literacy, the POGIL Method, and iPads into a Foundational Studies Program. The Journal of Academic Librarianship, v. 41, n. 2, p. 155-169, 32015.

MUCCHIELLI, A. Les sciences de l'information et de la communication. 2. ed. Paris: Hachette, 1998.

ORGANISATION FOR ECONOMIC COOPERATION AND DEVELOPMENT. OECD Guide to Measuring the Information Society 2011: OCDE, 2011.

PASSARELLI, B. et al. Identidade conceitual e cruzamentos disciplinares. In: PASSARELLI, B., SILVA, A.D. \& RAMOS, F. (Orgs.) e-Infocomunicação: estratégias e aplicações. São Paulo: Senac, 2014.
PERROTTI, E.; PIERUCCINI, I. A mediação cultural como categoria autônoma. Informação \& Informação, v. 19, n. 2, p. 01-22, 2014.

PHANG, A.; SCHAEFER, D.J. Is ignorance bliss? Assessing Singaporean media literacy awareness in the era of globalization. Journalism \& Mass Communication Educator, v. 64, n. 2, p. 156-172, 2009.

PILEROT, O. A practice-based exploration of the enactment of information literacy among PhD students in an interdisciplinary research field. Journal of Documentation, v. 72, n. 3, p. 414-434, 2016.

PISTÉ BELTRÁN, S. Evaluación de competencias en información para el aprendizaje y la investigación en universidades mexicanas. 2015 Universidad Carlos III de Madrid, 2015.

SÁNCHEZ-NAVARRO, J.; ARANDA, D. Internet como fuente de información para la vida cotidiana de los jóvenes españoles. El profesional de la información, v. 20, n. 1, p. 32-37, 2011.

SANTOS, C.A.; CASARIN, H. Habilidades informacionais abordadas em instrumentos de avaliação de competência informacional. Informacao \& Sociedade, v. 24, n. 3, p. 135-144, 2014.

SIEMENS, G. Conociendo el conocimiento: Nodos Ele, 2010.

SPIRANEC, S.; ZORICA, M.B.; KOS, D. Information literacy in participatory environments: the turn towards a critical literacy perspective. Journal of Documentation, v. 72, n. 2, p. 247-264, 2016.

VARELA, A.; BARBOSA, M.A. Acesso ao conhecimiento, mediaçao e multirreferencialidade. IX Congreso Isko-España, Valencia, v. 9, p. 111-125, 2009.

WALSH, A. Information literacy assessment: Where do we start? Journal of Librarianship and Information Science, v. 41, n. 1, p. 19-28, March 2009.

WILSON, C. Alfabetización mediática e informacional: proyecciones didácticas. Comunicar: Revista Científica de Comunicación y Educación, v. 20, n. 39, p. 15-24, 2012. 